Unsere Experten beraten Sie bei kniffeligen medizinischen Fragestellungen aus Ihrer Praxis.

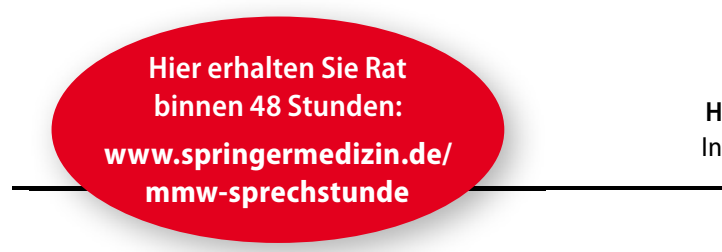

Prof. Dr. med. Hermann S. FüeßI Internist, München
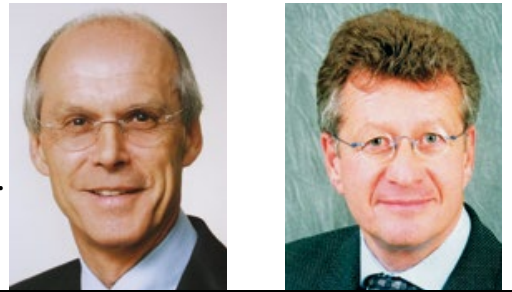

Dr. med.

Peter Stiefelhagen

Internist, Hachenburg

\title{
Kinder-Dermatologie
}

\section{Seit diesem Winter wächst der Ausschlag}

\section{?}

Dr. Anke Brattig, Biebertal: Einer meiner Patienten, ein Junge im Alter von 11 Jahren, leidet seit einigen Jahren an einem Hautausschlag. Anfangs trat dieser nur vereinzelt in den Wintermonaten eher streckseitig an den Beinen auf. In diesem Winter breitete er sich jedoch großflächig an den unteren Extremitäten, vereinzelt auch an den Armen aus. Er juckt zunehmend, schuppt aber nicht. Ein Abstrich auf Pilze war negativ. Eine Kortisonbehandlung führte nur vorübergehend zu einer Besserung.

Bei dem Jungen wurden im Oktober 2016 Unverträglichkeiten auf Gluten, Milcheiweiß und Vollei festgestellt. Gegen eine Dermatitis herpetiformis Duhring sprechen fehlende Bläschen.

I MMW-Experte Stiefelhagen: Es ist schwierig, nur aufgrund der Fotos eine akkurate Diagnose zu stellen, aber meines Erachtens handelt es sich bei den Hautveränderungen um eine atopische Dermatitis. Dafür sprechen die Anamnese und der Hautbefund. Sie sollten den Patienten aber auf jeden Fall einem Dermatologen vorstellen.

MMW-Experte FüeßI: Besonders aufschlussreich finde ich das Bild in stärkerer Vergrößerung. Hier hat man den Eindruck, dass die Primäreffloreszenzen punktförmig verteilt sind und es sekundär zu einer eher flächenhaften Dermatitis gekommen ist. Dieses Verteilungsmuster lässt an eine Follikulitis
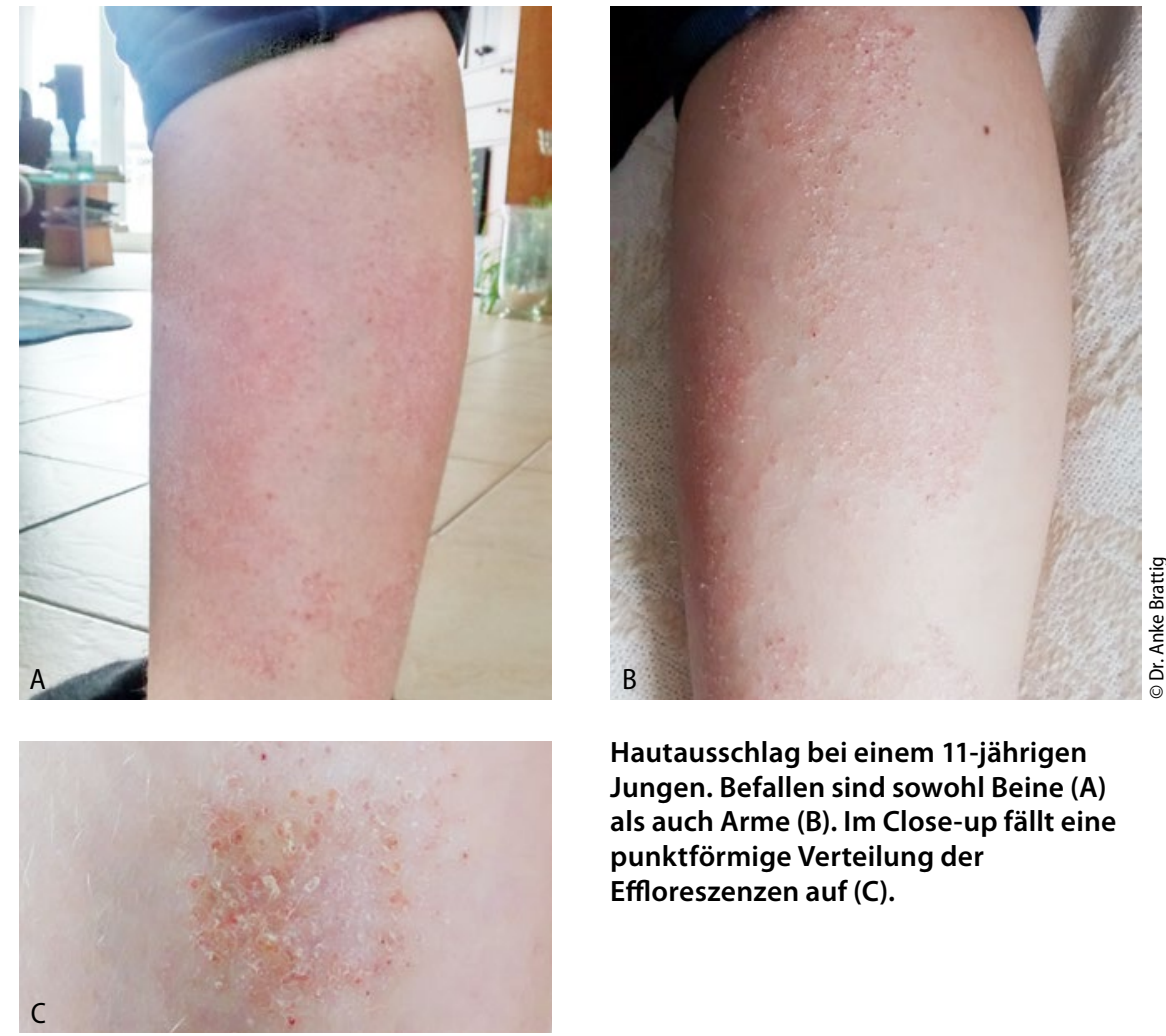

simplex denken, wenngleich es sich auf dem dargestellten Bild bereits um einen in Abheilung befindlichen Zustand handelt. Wegen des Juckreizes wäre auch an eine chronische follikuläre Pyodermie zu denken.

In dem Fall würde ich eine antibiotische Therapie dennoch nicht für notwendig halten, da der Befund nicht sehr ausgedehnt ist. Eine antiseptische Behandlung mit Zink-Schüttelmixturen mit Zusatz von Triclosan $2 \%$ oder Chlorhexidin dürfte ausreichen.
Hautausschlag bei einem 11-jährigen Jungen. Befallen sind sowohl Beine (A) als auch Arme (B). Im Close-up fällt eine punktförmige Verteilung der Effloreszenzen auf (C).

Bei chronischem Verlauf ist immer auch an eine Candida-Follikulitis oder eine chronische follikuläre Trichophytie zu denken. Es wäre von Interesse, wie der negative Pilznachweis durch „Abstrich“ zustande kam, denn hier kann auch viel schiefgehen. Das Schabematerial sollte auf einem Glasobjektträger in Gegenwart von 15\%iger Kalilauge unter einem Deckgläschen für eine Stunde in einer feuchten Kammer aufbewahrt und anschließend im Hellfeldmikroskop beurteilt werden. 